\title{
RETRACTED ARTICLE: Internet of vehicles and autonomous systems with Al for medical things
}

\author{
Taher M. Ghazal ${ }^{1,2} \cdot$ Raed A. Said ${ }^{3} \cdot$ Nasser Taleb $^{3}$
}

Accepted: 8 July 2021 / Published online: 22 July 2021

(C) The Author(s), under exclusive licence to Springer-Verlag GmbH Germany, part of Springer Nature 2021

The Editor-in-Chief and the Publisher have retracted this article. This article was submitted to be part of a guestedited issue. An investigation concluded that the editorial process of this guest-edited issue was compromised by a third party and that the peer review process has been manipulated. Based on the investigation's findings the Editor-in-Chief therefore no longer has confidence in the results and conclusions of this article. None of the authors has responded to correspondence from the Publisher about this retraction. The online version of this article contains the full text of the retracted article as Supplementary Information.

Springer Nature or its licensor (e.g. a society or other partner) holds exclusive rights to this article under a publishing agreement with the author(s) or other rightsholder(s); author self-archiving of the accepted manuscript version of this article is solely governed by the terms of such publishing agreement and applicable law.

Taher M. Ghazal

Taher.ghazal@skylineuniversity.ac.ae

1 Skyline University College, Sharjah, UAE

2 Universiti Kebangsaan Malaysia (UKM), Bandar Baru Bangi, Malaysia

3 Canadian University Dubai, Dubai, UAE 